\title{
La cultura escrita en el Mundo Atlántico colonial: Brasil y América del norte. Claves historiográficas, retos y perspectivas ${ }^{1}$
}

\author{
por \\ Carlos Alberto González Sánchez \\ Universidad de Sevilla
}

Este artículo pretende hacer una valoración crítica de la investigación sobre la cultura escrita de Brasil y Norteamérica coloniales, con el fin de plantear un balance historiográfico que nos permita una perspectiva comparativa con los estudios realizados sobre el resto del continente americano. En última instancia, intenta ofrecer unas nuevas perspectivas de estudio fundamentadas en la necesidad de una historia común de las Américas, que puedan superar los tópicos y concepciones dispares que deforman la historia del Mundo Atlántico.

PALABRAS CLAVE: cultura escrita; historiografia; mundo atlántico; Brasil; Norteamérica.

\section{INTRODUCCIÓN}

Desde los años ochenta del siglo XX, la historiografía sobre la cultura grafica (libros, escritos, lecturas e imágenes) del Mundo Atlántico de la era colonial está alcanzando, siquiera en cantidad, unas cotas dignas de interés; en buena medida gracias al auge que, a la vez, venía experimentando la denominada «nueva historia cultural». Por ello decido ahora prestarle atención, no pretendiendo un exhaustivo estado de la cuestión, inviable en el espacio disponible, pero sí planteando unas reflexiones cualitativas en torno a las

${ }^{1}$ Este trabajo se inscribe dentro del Proyecto I+D+I Inquisición, cultura y vida cotidiana en el Mundo Hispánico (siglos XVI-XVIII), Ref. HAR2011-27021, del Ministerio de Economía y Competitividad. 
perspectivas de estudio existentes, sus ejes metodológicos, interpretaciones, resultados y retos pendientes. Una empresa colmada de dificultades, dado lo variopinto de las áreas geográficas y las distintas experiencias históricas que abarca el denominado Mundo Atlántico; un nudo gordiano en el que confluyen las colonias de España, Portugal, Gran Bretaña y, en menor medida, Francia y Holanda. Una empresa que pretende analizar, en última instancia, el impacto de la cultura occidental en las civilizaciones autóctonas del Nuevo Continente y el acervo que aportó la población africana allí trasplantada a la fuerza. Todo un maná de relaciones, contactos e intercambios culturales, con un desarrollo propio, donde, a mi modo de ver, resalta más una simbiótica diversidad y el mestizaje de trayectorias coloniales similares, que los particularismos, disparidades y divergencias auspiciadas en determinados enfoques historiográficos. Ya sea el de una actitud intelectual, eurocéntrica, demasiado atenta al complejo y estricto aparato jurídico-institucional de dominio que emplearon las metrópolis; o el de las visiones nacionalistas y ensimismadas que desfiguran la verdadera esencia intercultural de las repúblicas que nacieron tras el proceso independentista del siglo XIX. Más, el protagonismo de la norma, certera en aquella realidad, con frecuencia, y por no reportar su cumplimiento beneficio o utilidad alguna, fue asiduo objeto de múltiples transgresiones en la vida cotidiana ${ }^{2}$.

Estos novedosos posicionamientos se están saldando con valiosas investigaciones que van más allá del análisis aislado de referentes locales, regionales o nacionales, o sea, desconectados del ámbito global-cultural en el que estaban inmersos y desarrollaron su historia ${ }^{3}$. La superación de estas supuestas y artificiales fronteras ideológicas, además de interesadas, es una de las premisas de una diferente historiografía del Mundo Atlántico que no pocos ya estamos reivindicando y confeccionando, al arrimo de una perspectiva transnacional y del método comparativo. Estos dos flancos nos pueden situar ante la genuina constitución de los fundamentos de aquel fenómeno histórico. Un buen acicate de estos propósitos son, desde tiempo atrás, los reclamos de John Elliott -quien me sugirió la idea de este artículo- sabiamente materializados en su monumental Imperios del Mundo Atlántico, un obra concebida según los postulados, una historia común de América, que estoy desplegando y subyacen en el cometido de estas páginas. De ahí que otorgue un especial relieve a la historiografía sobre la cultura escrita, desde la segunda mitad del siglo XX hasta hoy, de Brasil y de los Estados Unidos, con

\footnotetext{
2 Véase Lafaye, 1990: 229-261.

${ }^{3}$ Este contexto historiográfico es analizado por Bailyn, 2005. Suárez, 56 (Charlottesvilla, 2003-2004). González Sánchez, 2008.
} 
el fin de compararla con la de los países hispanoamericanos; ya que junto con Brasil y Estados Unidos conforman los tres grandes contextos coloniales del Mundo Atlántico. Si bien del imperio español, antes que un preciso escrutinio de la investigación en cierne, voy a destacar una serie de hitos explícitos de la problemática en estudio; pues, a diferencia de los territorios portugueses y británicos, los españoles disponen de recientes estados de la cuestión y, en general, de un mejor conocimiento ${ }^{4}$.

\section{BRASIL}

En Brasil la historiografía sobre la cultura escrita de la era colonial, al igual que del resto del Mundo Atlántico, ha venido centrando su atención en la historia del libro, un campo de estudio que, hasta no hace mucho, estuvo casi monopolizado por bibliógrafos y bibliófilos. A ellos, como consecuencia de una especial preocupación por las fuentes, debemos unos repertorios y recopilaciones de sumo valor y que están en el punto de partida de las investigaciones posteriores, aunque con unos fines distantes a los de la nueva historia cultural de hoy. Progresivamente, y por móviles diversos, la temática fue atrayendo a investigadores interesados en hacer del libro un elemento de la vida cotidiana, sirviéndose para ello de la documentación notarial, sobre todo de inventarios post mortem, tradicionalmente la fuente por antonomasia de la historia del libro, de su circulación y posesión. Una aportación pionera al respecto, aunque puntual, fue la de Alcântara Machado en torno al perfil cultural de los bandeirantes, realizada con los libros presentes en los inventarios de bienes del Archivo del Estado de Sâo Paulo, que manejó en la elaboración de un capítulo específico de su obra Vida e morte do bandeirante (Sâo Paulo, 1929) 5 .

A partir de los años cuarenta del siglo XX, con discreción, va aumentando la nómina de los interesados en el libro del Brasil colonial. Entre ellos cabe destacar a Carlos Rizzini (1946) y su trabajo O livro, o Jornal e a Tipografia no Brasil (1500-1822) ${ }^{6}$, en el que aborda factores fundamentales de los medios de comunicación propios del libro y la prensa periódica: la censura, la educación, las academias literarias o los lectores. En este estudio predomina

\footnotetext{
${ }^{4}$ Mencionar a Rueda Ramírez, 2005. Thomas y Stols, 2009. García Aguilar y Rueda Ramírez, 2010. González Sánchez, 2011.

${ }^{5}$ Machado, 1980. En esta nota y en las restantes citamos las ediciones más recientes de las obras mencionadas.

${ }^{6}$ Rizzini, 1988.
} 
el análisis de los contenidos de librerías y bibliotecas, tanto privadas como institucionales, casi siempre para ponerlos en relación con fenómenos de gran alcance, como el alzamiento revolucionario de 1789 en Minas Gerais, la «Inconfidencia Mineira» (Frieiro, 1957) o la Conjuración de Bahía de 1793-98 (Dias Tavares, 1959) ${ }^{7}$. En cualquier caso, aunque por otros fines, estos autores pusieron de relieve la riqueza y posibilidades de la documentación (la censura, la legislación, relatos de viajeros...), a pesar de que algunos trabajos solo fueron artículos sueltos o meras transcripciones de repertorios bibliográficos. Pero de justicia es reconocerles la apertura de la senda por la que todavía hoy transita la mayoría de los historiadores de la cultura brasileña colonial. Esta tendencia continúa, en los años setenta, con Katia de Queiros Matosso y María Beatriz Nizza da Silva ${ }^{8}$. A la vez, Rubem Borba de Moraes, entusiasmado con la línea de R. Darnton, contempla las bibliotecas, el comercio del libro, la censura y las tipografías, en una obra de referencia obligada: Livros e Bibliotecas no Brasil Colonial; años atrás ya había publicado Bibliografía brasileira do período colonial, un catálogo comentado de las obras, editadas antes de 1808, de autores nacidos en Brasil ${ }^{9}$.

Pese a los avances y logros mencionados, todavía en 1997 Luiz Carlos Villalta -uno de los mejores representantes de la historia de la cultura escrita brasileña actual-afirmaba que la historia del libro del Brasil colonial estaba en gran parte por hacer, y que eran muchas las lagunas historiográficas vigentes y necesitadas de atención ${ }^{10}$. La misma impresión sigue teniendo en 2008 Marília Ribeiro ${ }^{11}$, en particular cuando se refiere al periodo anterior al gobierno del Marqués de Pombal, una certeza manifiesta en uno de los rasgos más notorios del desarrollo de la investigación: su concentración en el último tercio del siglo XVIII y los dos decenios iniciales del XIX. Las causas que determinan esta cronología son diversas, siendo la primera de todas la escasez y dispersión de las fuentes nacionales disponibles hasta 1750. El resultado no sólo de una inadecuada o inexistente política de conservación sino ante todo del devenir de la colonización portuguesa durante los siglos XVI y XVII, excesivamente centrada en la costa y en torno a las grandes plantaciones allí establecidas; donde predominaba la mano de obra esclava frente a una minoría europea de

\footnotetext{
${ }^{7}$ Frieiro, 1981. Dias Tavares, 1959. Coetáneo de Tavares es Diniz, 1959: 333-344. También Éllis, 1957: 387-447. Ribeiro de Lessa, 1946: 339-345.

${ }^{8}$ Queiros Mattoso, 1978.

9 Borba de Moraes, 1969; 1979.

10 Villalta, 1998; muy interesante son sus reflexiones al respecto en 21 (Lisboa, 2005): 165-185.

${ }^{11}$ Ribeiro, 2008. A esta autora y a Luiz Carlos Villalta debemos agradecer la ayuda que nos han prestado para la redacción de este trabajo.
} 
hacendados, mercaderes, funcionarios, viajeros y aventureros. Sin olvidar, en este contexto, el protagonismo esencial de los misioneros de la Compañía de Jesús ${ }^{12}$. No exageraríamos si dijéramos que la historia de la cultura escrita de dicha etapa, y en buena medida de la posterior, suele aparecer liderada y mediatizada por los jesuitas. El libro, y el escrito en general, es la consecuencia inmediata de sus apetencias y necesidades, para uso particular y, en especial, como útiles de sus misiones y centros de enseñanza.

No será, pues, hasta finales del XVII, a raíz del descubrimiento de las minas de oro y la presión territorial de España, cuando Portugal comience a interesarse de manera decidida por el interior del país y los vacíos costeros. De ahí el progresivo auge que irán adquiriendo Minas Gerais y localidades como Río de Janeiro, Sâo Paulo, Bahía, Pernambuco o Maranhao, la génesis del Brasil independiente ${ }^{13}$. De otro lado, no menos determinante es la rigurosa centralización de los asuntos coloniales en Lisboa, característica de la política portuguesa y, en consecuencia, de la documentación resultante en la metrópoli. Esta circunstancia también subyace en la ausencia de imprentas en el Brasil colonial, otro de los factores cruciales a tener en cuenta a la hora de considerar la escasez de las fuentes locales. La dispersión antes mencionada, a su vez, se acentúa en todo lo referente a los archivos de los órganos gubernamentales responsables de la censura, producción y expedición de libros desde Portugal hasta 1768: inquisitoriales, diocesanos o del Desembargo do Paço.

El 5 de abril de 1768 se instituyó en Lisboa, por orden del Marqués de Pombal, la Real Mesa Censoria, organismo que unificó el sistema de censura y vigilancia de los libros, generando unos fondos documentales más ricos y homogéneos sobre el control y la circulación de productos tipográficos en el reino portugués y sus colonias. A ello se debe que hoy los archivos lisboetas guarden -bajo el nombre de «Catálogo para Examen de los Libros para que Salgan del Reino con Destino a Brasil»- millares de solicitudes de autorización o licencias de embarque, para el envío de material impreso al otro lado del Atlántico. Este procedimiento de interdicción se mantuvo hasta 1826, año en el que Portugal reconoció la independencia de Brasil, de hecho acaecida en 1822. Antes, en 1808, a causa de la invasión napoleónica, la Corte portuguesa se había trasladado a Río de Janeiro, un diferente emplazamiento de la Corona que también conlleva el establecimiento en la nueva capital de la Mesa de Desembargo do Paço, institución colonial, que ya llevaba tiempo funcionando en la metrópoli, encargada de fiscalizar la llegada de libros y, en última instancia, de evitar la introducción de textos sin licencia en tierras

\footnotetext{
12 Todo un clásico es Leite, 1938-1950.

13 Bennassar, 1980. Lockhart y Schwartz, 1992. Fausto, 2005.
} 
brasileñas. Esta disyuntiva, en los últimos diez años sobre todo, ha favorecido estudios sobre los textos que oficialmente circulaban en la colonia lusitana, pero todavía urge incrementar nuestras nociones acerca de la difusión y posesión de obras prohibidas ${ }^{14}$.

Un horizonte más nítido, del mismo modo, tenemos de la legislación que regulaba la censura previa y el cuidado de imprentas, libreros, editores y bibliotecas del Reino desde 1540: la pragmática sobre la impresión de libros de 1558, la reglamentación censoria de las Ordenaçôes Filipinas de 1603 y las leyes de 1576 y 1588, que prohibían la impresión de libros sin la licencia correspondiente. Sin embargo, no se ha explotado lo suficiente la información derivada de esta normativa. Un tesitura similar padecen las noticias de las visitas de navíos, cuyas actas custodia la sección de Inquisición del Arquivo Nacional da Torre do Tombo en Lisboa. Una política que, para todo su imperio, puso en marcha Portugal hacia 1550, regulada por el cardenal D. Enrique en 1561 en $O$ Regimento dos Visitadores das Naus ${ }^{15}$. Aunque no será una práctica regular sino a partir de 1580, cuando comienza el despliegue de los comisarios inquisitoriales por los diferentes puertos portugueses. De nuevo aquí los jesuitas aparecen como los principales ejecutores de este sistema de vigilancia; no obstante, en Brasil, la figura del Visitador de Nau no será una realidad hasta la llegada del padre Manoel de Lyma a mediados del siglo XVII, por haber sido nombrado para dicha función en Maranhao ${ }^{16}$. Tampoco han sido objeto de un profuso tratamiento, salvo algunas aproximaciones de interés, los procesos inquisitoriales del tribunal de Lisboa, jurisdicción a la que pertenecía Brasil ${ }^{17}$.

A pesar de los inconvenientes expuestos, es cierto que desde la década de los ochenta del siglo XX se está produciendo un considerable aumento del número de investigadores, de diferentes áreas de conocimiento (historia, literatura, lingüística, educación, antropología), preocupados por el estudio del libro y la lectura del periodo colonial. Esta vocación interdisciplinar es un rasgo sobresaliente que, sin duda, deparará perspectivas más eficaces y enriquecedoras; y la influencia en aquel país de las novedades metodológicas internacionales, con el protagonismo de las reflexiones y sugerencias de R. Chartier y R. Darnton. Es por ello que, con mayor o menor acierto, se vienen asumiendo conceptos y retos de alguna utilidad: la crítica textual, el imaginario

${ }^{14}$ Con la información de la Real Mesa han trabajado Abreu, 22 (Sâo Paulo, 2002):131163. Villalta, 8 (Belo Horizonte, 1995): 19-52. Verri, 2006.

15 Fundamental es Andrada e Silva, 1854.

16 Véase Bethencourt, 2000. Siquiera, 1978.

17 Además de los títulos ya citados, cabe destacar Mott, 1989. Ribeiro, 2008. 
y la representación, la apropiación, la recepción, las prácticas lecto-escritoras, la bibliografía material y las estrategias de autores y editores en la imposición de una determinada ortodoxia. En definitiva, un horizonte alternativo que hace del libro un elemento social, no sólo objeto de lectura y escritura sino también de una diversa gama de prácticas: lecturas diversas, posesión, compra-venta, conductas, control o memoria colectiva.

Sin embargo, ha sido y es notorio (más que una historia de la lectura, como ha ocurrido en Europa y el resto de la América ibérica), el predominio de la investigación sobre la circulación y posesión del libro a través de los inventarios post mortem y otros habituales documentos notariales. Estas fuentes han sido empleadas también para ver el impacto de la alfabetización entre los diferentes grupos sociales, partiendo de la posibilidad de firmar, como indicio. Mas, como fuere, es esta una tarea que estimamos todavía incompleta, previa e indispensable si se quieren alcanzar las metas antes reseñadas. Aquí hemos de nombrar a Jorge de Souza Araújo, autor en 1988 de una monumental tesis doctoral que ofrece una visión general del país sobre las bibliotecas, el comercio de libros y el perfil del lector, mejor poseedor, entre los siglos XVI y $\mathrm{XIX}^{18}$. Un trabajo, muy erudito y ampliamente documentado, en el que prima la descripción sobre la interpretación. Otros historiadores, en cambio, optaron por restringir el enmarque espacial y depurar las técnicas cuantitativas con el fin de asumir retos más suculentos, además de la circulación y posesión, cual la interdicción, la conexión de los libros inventariados con determinadas ideologías y movimientos culturales, políticos y revolucionarios, la imposición de la ortodoxia religiosa y actitudes ideales y el consumo de obras literarias ${ }^{19}$.

En este panorama despuntan iniciativas como el trabajo de Maria B. Nizza, Cultura Brasileira: da reforma da Universiadade à Independencia do Brasil, en el que trata prácticas lectoras de textos ilustrados (Voltaire y Bielfeld), las primeras imprentas y ediciones brasileñas, y el impacto de otros formatos tipográficos: los folletos, las gacetas y los periódicos. En una línea más clásica se inscribe la monografía de Thábata Araújo, Homens e Livros em Vila Rica (1750-1800), un preciado estudio sobre dicha ciudad minera en el que observa la combinación, en materia libraria, entre la tradición y la innovación, pese a ser muy escueto el impacto de las Luces y lo común de los libros profesionales en las fuentes manejadas. Mejores cualidades contemplamos

18 Souza Araújo, 1999.

19 Bastos Pereira das Neves, 33 (Coimbra, 1999): 665-697; 23 (Lisboa, 1992): 61-78. Horta Nunes, 1994. Mezan Algranti, 1995:109-124; 2002. Carneiro, 2002. Gomes Leite, 24 (Belo Horizonte, 2001): 217-226. Araújo Antunes, 6 (Juiz de Fora, 2000): 9-20. Abreu, 69-70 (París, 2008a): 11-35. 
en la tesis doctoral de Luiz Carlos Villalta, Reformismo Ilustrado, Censura e Prácticas de Leitura: Usos do Livro na América Portuguesa (Universidad de Sâo Paulo, 1999), realizada con 911 inventarios post mortem, entre 1714 y 1822, de Mariana, otra localidad de Minas Gerais, región que, según vamos viendo, adquiere una destacada posición en la investigación. Villalta, conforme a la historiografía francesa y española, con un esmerado análisis cuantitativo estudia las dimensiones de la alfabetización, la distribución social, profesional y educativa, la composición de las bibliotecas, las diferentes actitudes cotidianas en torno al escrito $y$, también, el grado de eficacia de la censura, que dirime a través de la posesión de libros prohibidos y del peso de la literatura de ficción en la época del reformismo ilustrado ${ }^{20}$. Villalta en la actualidad centra sus desvelos en la historia de la lectura y la acción censoria, con un entusiasmado interés, y pericia reflexiva, por la recepción y apropiación, la representación y el imaginario a través de la literatura de ficción, en concreto la francesa y su persecución oficial. A la par que la eclosión de las Luces y su influencia en brotes político-revolucionarios ${ }^{21}$.

Un revulsivo palpable vienen desempeñando las contribuciones hechas desde la historia de la literatura, un frente preocupado por la inserción social de los diversos géneros discursivos, el lector y las técnicas de lectura, las estrategias editoriales, la crítica textual y la génesis de una literatura nacional ${ }^{22}$. Es esta dirección es Márcia Abreu una guía indiscutible, que ya en 1993 nos regaló una excelente obra sobre la literatura de cordel y su funcionalidad en el nordeste brasileño del siglo XVIII ${ }^{23}$. Pero paulatinamente se fue sumergiendo en las listas de libros presentes en la documentación de los tribunales censorios portugueses, con el fin de apreciar los remitidos desde Lisboa a Río de Janeiro desde 1768 a 1822 y, en última instancia, el papel que jugaron las bellas letras, su verdadero objetivo. Con esta documentación y con los mismos textos aborda diferentes flancos de la historia de la lectura: las normas morales de uso y recepción, la didáctica lectora inserta en los discursos literarios, la censura y, combinando inventarios de bienes y surtidos de libreros, el grado de difusión y popularidad de los libros objeto de su análisis ${ }^{24}$. En 1999 dirigió la obra colectiva Leitura, História e História da Leitura, que sirve de orientación en estas coordenadas que comentamos y donde figura un elenco

${ }^{20}$ Nizza da Silva, 1999. Araújo de Alvarenga, 2003. Villalta, 1999.

${ }^{21}$ Villalta, 1992: 267-295; 8 (Belo Horizonte, 1995):19-52; 2000:183-212; 2 (Gijón, 2006):128-160; 7 (Gijón, 2008): 98-117.

${ }^{22}$ En este terreno destacan Lajolo y Zilberman, 1996.

${ }^{23}$ Abreu, 1999.

${ }^{24}$ Ibidem: 249-260; 2000b: 201-206. 
de autores apasionados con la temática. No obstante, es su libro Os Caminhos dos livros el que recoge una buena muestra de sus principales aportaciones hasta el presente, enmarcadas en Río de Janeiro, mas con la pretensión de ir ampliándolas al resto de la América portuguesa ${ }^{25}$.

En la actualidad, la investigación sigue insistiendo en la circulación comercial y posesión del libro, así como en las prácticas y los espacios de lectura, ámbitos en los que aun queda mucho por hacer. Dentro de estos ámbitos se está dando prioridad a los intereses políticos que mediatizaron el comercio de productos tipográficos, la composición de las bibliotecas, la censura y los hábitos lectores, volcados estos últimos en la literatura laica, en particular la de ficción, la novela, género en el que se está ensayando, con resultados dispares, la compleja aplicación de los fundamentos del imaginario, la representación, la apropiación y la recepción. Una muestra ejemplar de estas nuevas realizaciones las tenemos en el reciente libro Trajetórias do Romance. Circulaçâo, leitura e escrita nos séculos XVIII e XIX ${ }^{26}$, una compilación interdisciplinar, de filólogos e historiadores, que recoge una nómina de autores (28) y argumentos hoy día en discutida boga. Estas tendencias actuales también pueden apreciarse en el programa-preactas del XVI Encontro Regional de História ANPUH-Minas Gerais, celebrado en Belo Horizonte en julio de 2008, donde hubo un simposio temático dedicado a la historia del libro y la lectura, agraciado con una muy nutrida audiencia y participación de jóvenes investigadores de todo el país, indicio del avance y entusiasmo que este campo historiográfico va cosechando ${ }^{27}$.

Acariciamos, pues, un futuro prometedor, prolífico y eficaz, para la historia de la cultura escrita del Brasil colonial, pero todavía quedan muchos retos pendientes porque quizás no se hayan superado del todo los presupuestos de una primera fase que debe insistir en la resolución de dos interrogantes de partida: qué libros y escritos y qué autores, lectores y poseedores. Un propósito que, a la vista del panorama expuesto, requiere más atención que la esquiva historia de la lectura. Por ello hay que seguir indagando, en Brasil y en Lisboa, en la documentación notarial disponible y en otras fuentes alternativas ya mencionadas; hay que superar unos encuadres geográficos hasta hoy reducidos a determinadas regiones y localidades (Minas Gerais, Río de Janeiro, Salvador, Pernambuco); y, sobre todo, hay que superar límites cronológicos excesivamente arraigados en la segunda mitad del siglo XVIII y

25 Ibidem, 2003; 7 (Gijón, 2008b):118-141.

${ }^{26}$ Ibidem, 2008c. Abreu y Schapochnik, 2005. Abreu y Bragança, 2010.

${ }^{27}$ XVI Encontro Regional de História ANPUH-Minas Gerais, Belo Horizonte, Universidad Federal de Minas Gerais, 2008. 
primer tercio del XIX y prestar atención a los olvidados siglos XVI y XVII. La ampliación de los enmarques espacio-temporales, requisito historiográfico imprescindible, puede ayudarnos a entender y valorar mejor las cuestiones planteadas para fechas posteriores. En esta directriz cabe mencionar la labor que Marília Ribeiro está llevando a cabo con los libros de los colegios y misiones jesuitas del siglo $\mathrm{XVI}^{28}$.

La historia de la cultura escrita de la América portuguesa colonial, obvio es, se ha restringido a la historia del libro y otros productos tipográficos (pliegos, folletos y periódicos), arrinconando vertientes tan decisivas, y usuales en la época, como el mundo de las imágenes ${ }^{29}$. Pero es la escritura, el escrito y su función social, el frente que requiere mayor atención y mayor número de investigadores capaces de desplegar los parámetros de la renovación de la paleografía liderada por Armando Petrucci y, en España, Antonio Castillo. En esta línea, no obstante, ya se están haciendo aportes dignos de mención, como los coloquios internacionales organizados por Leila Mezan Algranti y Ana Paula Megiani, en 2007 y 2009, acerca de la escritura y sus medios de transmisión. También cabe mencionar la labor de Adriano Angelita o Luciana Lopes dos Santos en torno a la correspondencia epistolar, y el encomiable trabajo de Eduardo Neumann sobre la escritura, a través de cartas y billetes, de los guaraníes reducidos en las misiones ${ }^{30}$. Esperemos que todas estas iniciativas vayan despejando un paisaje esperanzador, que ya lo es. En fin, sirva esta escueta e incompleta panorámica como aproximación a un complejo, y rico en matices, campo historiográfico brasileño, de cuya producción, en un país tan grande y poblado, resulta muy complicado tener un preciso estado de la cuestión. El tema cada día atrae a más estudiantes e investigadores y existe hoy un piélago de autores de un sinfín de disertaciones de maestría, tesis doctorales, monografías, artículos, ponencias y demás publicaciones científicoacadémicas difíciles, en extremo, de controlar.

\section{La América del Norte}

La investigación sobre la cultura escrita en Norteamérica se ha concentrado casi al completo en las 13 colonias británicas de la costa este de los actuales Estados Unidos. Una menor atención, en cambio, ha recibido Canadá, aunque

\footnotetext{
28 Ribeiro, 2008.

${ }^{29}$ Una síntesis sobre esta temática, en reclamo de adeptos, es la que plantea França Paiva, 2006.

${ }^{30}$ Mezan Algranti y Megiani, 2007. Neumann, 7 (Gijón, 2008): 159-190.
} 
en la actualidad cuenta con estudios de gran interés ${ }^{31}$. América, no obstante, es un continente en el que, además de España, Inglaterra y Portugal, intervinieron otras potencias europeas como Holanda y Francia, que también detentaban dominios en el Caribe y en otras demarcaciones: territorios marginales, de escasa población blanca y muy ligados a la explotación de determinados recursos y al valor geoestratégico de sus enclaves geográficos, de vital importancia como plataformas del comercio y la navegación intercontinental ${ }^{32}$. Quizás a ello se deba que tampoco hayan sido objeto preferente de la historia cultural. Los estudios existentes se centran, al igual que en Brasil, en la segunda mitad del siglo XVIII y primeros años del XIX, debido a la relativa escasez de fuentes documentales autóctonas de las etapas anteriores. En el caso de los asentamientos británicos, la ausencia de la institución notarial complica aun más esta carencia informativa.

De entrada podemos decir que para el espacio británico el eje historiográfico ha girado en torno a la escritura, el libro, los periódicos, la edición y la lectura desde el comienzo del periodo colonial hasta 1790. Estas temáticas se enmarcan en tres grandes áreas de estudio: el tráfico precapitalista de productos tipográficos entre el Viejo y el Nuevo Mundo, los intercambios y sus vehículos culturales e intelectuales, y el desarrollo de la imprenta local ${ }^{33}$. Mas tampoco se han dejado de lado cuestiones imprescindibles como la alfabetización, la enseñanza, la censura, el debatido nacimiento de la libertad de prensa, la escritura y la oralidad o la difusión, a través del escrito, de determinados movimientos políticos y religiosos. Si bien, expertos en la materia, H. Amory en primer lugar, opinan que la historia del libro en la América británica es la historia de los libros importados de la metrópoli ${ }^{34}$. Una realidad que no nos debe llevar al olvido de la gradual emergencia de un competitivo comercio de libros en las colonias, en sus inicios dependiente del patronato del gobierno civil y eclesiástico y, a la vez, de las importaciones del exterior ${ }^{35}$. Un mercado continental, en definitiva, que no obvió estrategias (licencias y censuras) para la regulación y el control de textos, impresores y libreros. Todos estos parámetros maneja D. D. Hall a la hora de hablar de la génesis de una específica cultura letrada colonial, esencialmente organizada desde una concepción teológica

\footnotetext{
${ }^{31}$ Un estudio pionero es el de Tremaine, 1952. Más tardío, Parker, 1985.

${ }^{32}$ Sobre el Caribe Cave, 1987.

${ }_{33}$ Para el tráfico de libros han sido editados en microfilm los registros de exportaciones e importaciones coloniales de Inglaterra por Minchinton y French, 1974.

${ }^{34}$ Amory, 2005. Barber, 151 (Oxford, 1976): 185-224. Otro de los mejores de nuestros días, Hall, 1988: 1-47; 1996. También Raven, 2000a: 73-90; 2000b.

${ }^{35}$ Un clásico todavía imprescindible es Ford, 1917. Otra obra fundamental es la de Miller, 1974. Más reciente Franklin, 1980. Y sobre todo Amory, 2005.
} 
de la imprenta y otros referentes significativos, como el republicanismo de la nueva sociedad ultramarina ${ }^{36}$.

Una clave crucial de la cultura escrita de la temprana Norteamérica fue la decisiva mediatización que en ella ejercieron las ideas y prácticas de la reforma protestante, de ahí la supremacía de la Biblia, el libro por antonomasia que, en aquel mundo, se podía hallar en cualquier lugar. Una cultura bíblica compartida fue, por tanto, el verdadero fundamento de la vida cultural-religiosa de la América anglosajona, donde las Sagradas Escrituras resolvieron muchas de las tensiones entre las distintas comunidades religiosas allí establecidas ${ }^{37}$. No en vano, la posesión de biblias se convirtió en una acuciante necesidad, sujeta en todo momento a los suministros de la metrópoli, conforme a los derechos exclusivos de edición de las universidades de Oxford y Cambridge. Este monopolio, y los altos precios que ocasionaba, subyacen en el bajo nivel de ventas característico del mercado de libros en las colonias. Por ello los impresores de Nueva Inglaterra no cejaron hasta encontrar una argucia legal que les permitiera publicar la Biblia o, al menos, un texto parecido. Objetivo que haría realidad la pionera imprenta de Cambridge, fundada en 1638, que en 1640 logró manufacturar el popularísimo Bay Psalm Book (Salterio de la Bahía), primer libro publicado en las posesiones británicas. Virginia no tendría una imprenta permanente hasta 1730.

La Biblia, pues, impregnó toda la cultura colonial. Llegó a ser uno de los acicates esenciales de la enseñanza básica lecto-escritora pública y privada de los niños, y un manual habitual en el aprendizaje de la lectura ${ }^{38}$.

En Nueva Inglaterra y Virginia, de acuerdo a las leyes educativas estatales de la década de los 40 del siglo XVII, la familia asumía la responsabilidad esencial de la catequesis y la formación infantil, el medio ideal que aseguraría la promoción y consolidación de los preceptos de la religión y las normas jurídicas locales de la nueva sociedad. Sin embargo, la legislación de la época también preveía la escolarización regular en cada población con más de cincuenta familias. Estas disyuntivas han constituido uno de los principales flancos de la investigación, que, en función de la capacidad de firmar de los pobladores, ha dado resultados sorprendentes, si los comparamos con los índices europeos y del resto de América. Así en Virginia, la alfabetización entre hombres blancos aumentó de un $46 \%$ en 1640 a un $62 \%$ hacia 1710 ; mientras que en Nueva Inglaterra, con los mismos parámetros, el $60 \%$ de los

\footnotetext{
${ }^{36}$ Hall y Amory, 2000: 3. Hall, 2 (Gijón, 2006):108-127. Al igual Remer, 2000.

37 Hall, 1989. Wolf, 1988.

38 Véase Elliott, 2006: 300-331. Amory, 1989.
} 
hombres y el $30 \%$ de las mujeres estaban alfabetizados en 1660, cifras que suben al $70 \%$ y el $45 \%$, respectivamente, en torno a $1750^{39}$.

La cultura escrita también está presente en los intentos que los colonos llevaron a cabo para la evangelización de los indios, una empresa diferente y con mucha menos fortuna que la de la misión ibérica, que, debido a la iconoclasia protestante, confió casi exclusivamente en la palabra escrita. La iglesia anglicana, en cualquier caso y al contrario que la católica, a principios del siglo XVII no disponía de los medios necesarios ni de órdenes religiosas o evangelizadores militantes capaces de aceptar semejante reto. Pese a ello, en 1649 el Rump Parliament aprobó la creación de la Sociedad para la Propagación del Evangelio en Nueva Inglaterra, el principal instrumento misional metropolitano de apoyo a los clérigos anglicanos de ultramar. Otro recurso auxiliar ensayado fue la traducción a diferentes lenguas indígenas del Book of Common Prayer, y de la de la Biblia que hiciera John Eliot en Massachusett a mediados del XVII, terminada en 1659 y publicada en 1663. No obstante, la alfabetización de los indios fue en inglés, al menos hasta 1720, aunque el Henrico College, fundado en 1619 para dicho cometido, ni siquiera llegó a entrar en funcionamiento. Parecida fue la suerte del Indian College de Harvard, construido en 1655 y demolido en 1693; o la de los «pueblos de oración» impulsados por Eliot, una especie de reducciones de muy exigua aceptación entre unas tribus indígenas hostiles y muy reacias al cristianismo ${ }^{40}$. Nada tiene que ver esta historia con la de los centros de enseñanza superior, los colegios universitarios establecidos para la formación de futuros pastores puritanos y clérigos anglicanos: el Harvard College (1636) en Nueva Inglaterra y el College of William and Mary (1693) en Virginia.

Aquellos colonos, además de la Biblia, demandaban e imprimían almanaques, catecismos y otros textos devocionales y litúrgicos, especialmente el Book of Common Prayer de 1549, porque, en el protestantismo, junto con la predicación, el libro y la imprenta fueron instrumentos de enorme trascendencia y al servicio de sus prácticas religiosas ${ }^{41}$. Impresores y libreros, del mimo modo, se beneficiaron de las subvenciones de los gobiernos civiles, las iglesias y las sociedades filantrópicas; es más, los distintos movimientos socioreligiosos (cuáqueros, pietistas...) incluso desarrollaron sus propios medios de producción y distribución. Eso sí, monarcas y autoridades eclesiásticas siempre rechazaron el libre mercado del impreso con el fin de anular la circulación de discursos erróneos y nocivos, un requisito que la metrópoli persiguió emplean-

\footnotetext{
39 Rhys, 1982. Lockridge, 1974. Bailyn, 1960. Cremin, 1970. Gallegos, 1992.

40 Axtell, 2001. Cogley, 1999. Vaughan, 1995.

${ }^{41}$ Stout, 1986.
} 
do el mecanismo de control vigente en Inglaterra, basado en la concesión de licencias y permisos, de edición y venta, a través de la londinense Stationers' Company creada en $1557^{42}$.

Los libros importados y por exportar obligatoriamente tenían que pasar por Londres para su examen y calificación pertinente, con los consiguientes perjuicios que este método causaba a impresores, libreros y mercaderes, cuyos negocios en espera dependían de la lenta resolución de este sistema de censura previa; pero lo aceptaron porque les aseguraba prebendas exclusivas de publicación y negocio de ciertas obras. Estas restricciones quedaron debilitadas cuando en 1695 caducó la Ley de Licencias en Inglaterra, algo que no impidió que las autoridades reales, apoyadas por las asambleas coloniales, siguieran supervisando las prensas y los escritos en circulación, incluso con leyes específicas contra libelos blasfemos y sediciosos. El método, pese a sus altibajos, perduró, aunque el Copyright Act of Anne de 1710 sea un hito sin precedentes, pues se trata de la primera ley que reconoce los derechos de autor, uno de los grandes temas de estudio de la trayectoria historiográfica que estamos repasando.

Volviendo a la cuestión que aquí nos ocupa, hemos de decir que las directrices historiográficas, como para el resto de América, tienen su origen en la labor de eminentes bibliógrafos y bibliófilos desde principios del siglo XIX. Isaiah Thomas fue el autor de la primera historia del impreso de la América inglesa, The History of Printing in America (1810), cuyo objetivo no es otro que el estudio de la puesta en marcha y desarrollo de la imprenta en las colonias británicas, desde Canadá al Caribe. Su testigo lo recibe Joseph Sabin, quien en su monumental Bibliotheca Americana (1868-1936) confecciona un repertorio de libros publicados tanto en el Norte como en el Sur del continente americano desde su descubrimiento. Después vendría la Early American Poetry de Oscar Wegelin, que opta por el acopio de obras poéticas, en cualquier lengua, de autores nacidos o residentes en América, pero hasta la frontera con México ${ }^{43}$.

El siglo XX lo inaugura Charles Evans con un título emblemático: la colosal American Bibliography (1903-1955), en el que ensaya una bibliografía autóctona retrospectiva, conjugando la lengua, la nacionalidad, la religión y la escritura como factores constituyentes y distintivos de una genuina literatura nacional americana. Cabe también mencionar, de la primera mitad de la centuria, The Colonial Printer de Lawrence C. Wroth y, en particular, a Jacob Blanck, el padre de la Bibliography of American Literature (1955-1991),

42 Véase Clegg, 1997. Cushing, 1981.

43 Thomas, 1810; hay una edición neoyorkina de 1967. Sabin, 1868-1936. Wegelin, 1903. 
una recopilación de escritores norteamericanos y obras literarias autóctonas. Tampoco olvidamos a D. McMurtrie y R. Bristol ${ }^{44}$. Todos ellos incluyen en la categoría de libro a cualquier producto tipográfico local (hojas sueltas, pliegos, folletos, estampas); mas la idea de fondo que les mueve y predispone consiste en enfatizar y poner de relieve la originalidad y diferencia del impreso americano, mejor norteamericano, que, frente al importado de Europa, denominan «libro colonial».

Por libro colonial, pues, entienden, según coordenadas de nacionalidad y religión, lo que fue escrito, impreso y publicado por o para los colonos. No obstante, y a pesar de los postulados subyacentes y fines perseguidos, cientos de los títulos que registran son en realidad libros importados, un entramado, plagado de impresos ingleses, que ya contempló Edwin Wolf en los inventarios de bibliotecas y catálogos de surtidos de librerías coloniales ${ }^{45}$. Dicha definición, en suma, desprecia mucho de lo que allí se leía o estaba disponible e incluso margina obras que se imprimieron en el exterior para su exclusiva venta y consumo al otro lado del Atlántico. Pero lo peor es que esta manera de interpretar el pasado de la cultura escrita norteamericana ha llegado hasta nuestros días.

D. Hall, ante esta restricción conceptual, interviene en la diatriba con una noción de «libro colonial» mucho más amplia y abierta, alusiva a todo lo que los colonos importaron, compraron, imprimieron, reimprimieron, escribieron y leyeron, independientemente de su lugar de procedencia. Así, el apelativo «colonial» deliberadamente lo emplea para redundar en la continua dependencia de aquella cultura escrita del comercio transatlántico, o sea, del suministro metropolitano de impresos, papel, tinta, tipos o prensas, además de una amplia gama de prácticas culturales. Desde esta consideración, los colonos fueron figuras menores de un escenario dirigido desde los centros cosmopolitas del Viejo Continente; pero sin olvidar que intervenían en un tráfico de ida y vuelta, ni las originales y valiosas aportaciones de las poblaciones ultramarinas. Por tanto, «colonial» designa no sólo ciertas estructuras del imperio británico y de la economía atlántica, sino también una variedad de aspectos de la vida intelectual y de la identidad cultural coloniales ${ }^{46}$. Allí, sin embargo, los agentes del libro gozaron de una mayor libertad e independencia que en las posesiones españolas y portuguesas, como ocurría en muchas componendas vitales de dicha sociedad.

${ }^{44}$ Evans, 1903-1959. Wroth, 1922; 1938. Blanck, 1955; hay una edición de 2003 en Oak Knoll Press. McMurtrie, 1994; el original se publicó en Chicago en 1943. Bristol, 1962.

${ }^{45}$ Wolf, 1988. Shipton y Mooney, 1969. Tanselle, 1980: 319.

${ }^{46}$ Hall y Amory, 2000: 1-25. 
Con estos planteamientos David D. Hall y Hugh Amory -quizás los dos historiadores del libro norteamericano más relevantes- editaron en 2000 The Colonial Book in the Atlantic World, una gran iniciativa que bien podría servir de estímulo para otra similar de la América latina. Es el primer volumen de una empresa mayor, cuyo editor general es D. Hall ${ }^{47}$, que cubre desde los inicios del periodo colonial hasta 1995. De este modo, con mayor o menor acierto según cada capítulo, se ha tanteado un modelo de historia total del libro, con visión de futuro y para superar los escollos antes comentados e ir más allá de un mero estado de la cuestión; que bien resume lo que ha sido y es la historiografía norteamericana al respecto. Hemos de señalar, no obstante, que su «mundo atlántico» sólo lo conforman las colonias británicas de América, es decir, ignoran su verdadera amplitud geográfica, diversidad y riqueza cultural, marginando así a los espacios ibéricos, franceses y holandeses. "America», al igual, se reduce a los actuales Estados Unidos y, en el primer volumen, a las Trece Colonias del Norte. En definitiva, el Mundo Atlántico, dada su naturaleza y trayectoria histórica, continúa pidiendo a voces un tratamiento común que no sólo aborde las diferencias y excepciones de cada una de sus partes constitutivas, sino también sus grandes nexos en común. Urge, pues, hacer una historia de la cultura escrita americana en general, interdisciplinar, transnacional y comparativa, criterios propicios a la anulación de los defectos y tópicos vigentes que la deforman ${ }^{48}$.

Sea como fuere, la investigación que se ha venido desarrollando enfatiza en los continuos intercambios de impresos y prácticas entre el Viejo y el Nuevo Mundo, aunque desde una perspectiva excesivamente norteamericana y desconectada del resto de América. Esta visión a la vez se perpetúa en el universo de la escritura, la lectura y sus prácticas; y en la de los lectores y los escritores como actores de unas nuevas estructuras y corrientes ideológicas que promueve el escrito ${ }^{49}$. En tanto que simultáneamente conviven con otras más viejas y persistentes, resultando de su interacción distintas formas de sociabilidad y novedosos medios de producción cultural. Mas hoy día se están consolidando líneas de estudio, ya probadas en la historiografía europea, de gran impacto e interés ${ }^{50}$. De entrada, podemos traer a colación la concerniente a «oralidad-escritura-imprenta», con el fin de destacar cómo el primer parámetro, una categoría flexible, coexiste y complementa a los dos

47 Hall, 2000.

${ }_{48}$ Estos presupuestos son los que defiende Suárez, 56 (Charlottesvilla, 2003-2004): 140170.

49 Sobre cartas misivas Shields, 1996.

${ }^{50}$ Al respecto Davidson, 1989. Bailyn y Hench, 1980. 
restantes; porque no son excluyentes ni exhiben una evolución lógica, de ahí el protagonismo documental de las cartas misivas y de la predicación.

Otra cuestión alude al binomio «letrados-iletrados» (alfabetizados-analfabetos), sus circunstancias y significados, la ductilidad de sus relaciones y la identificación y contextualización de las estrategias mediante las cuales la población iletrada interviene en la cultura escrita. Una tercera vía, «Imprenta y espacio público», indaga (a partir de las reflexiones de Habermas), en la génesis de una república de las letras original en Norteamérica, proceso en el que influyen autoridad, política y religión, y en el que prevalece el ámbito local frente al nacional, y una supuesta mayor libertad de acción, expresión y pensamiento que en Europa ${ }^{51}$. Por último, «autoría y propiedad intelectual», para hacer de América del Norte un lugar primigenio del nacimiento del autor a raíz del temprano reconocimiento de sus derechos y autonomía literaria ${ }^{52}$. En cualquier caso, la historia americana del libro, y de la cultura escrita en general, en la actualidad no es un campo de investigación muy cultivado en los Estados Unidos, al menos en comparación con otras temáticas económicas, sociales, políticas y culturales de su pasado. Buena prueba de ello son las fechas de publicación de las obras que estamos citando. Incluso en sus universidades, los historiadores del escrito y sus circunstancias prefieren a Europa como encuadre geográfico de sus desvelos científico-académicos.

\section{El RETO ATLÁNTico}

La historiografía de la cultura escrita en América, según acabamos de ver, empieza a tener una cierta entidad y vitalidad, pero queda todavía mucho camino por recorrer, sobre todo si tenemos en cuenta la desconexión y la falta de criterios unificadores tocantes a líneas de investigación, metodología y fuentes documentales. Entre los factores determinantes de esta compleja situación destacan la extensión, diversidad geográfica y variopinta trayectoria histórica del Continente y sus diferentes circunscripciones territoriales. En Iberoamérica especialmente acuciante es la ausencia, precaria disponibilidad o mal estado de conservación de las fuentes coloniales, en buena medida consecuencia de los endémicos problemas económicos de sus distintos países, donde, en general, la escasez de infraestructuras archivísticas adecuadas y la desatención gubernamental son otros de los obstáculos primordiales. Estas dificultades las agravan aun más los excesos pasionales y patrióticos que impregnan ciertas

\footnotetext{
${ }^{51}$ Warner, 1990. Hall, 2 (Gijón, 2006): 108-127.

52 Bugbee, 1967. Rice, 1997. Woodmansee y Jaszi, 1994.
} 
historiografías nacionalistas, a veces el cauce de expresión de un discurso oficial resentido, victimista y reivindicativo, con fines espurios e interesados. Todos ellos resortes ideológicos que han ido restando cientificidad y fiabilidad a determinados planteamientos de su historia cultural.

Entre no pocos historiadores y filólogos hispanoamericanos ha persistido un indigenismo secuestrado y arbitrario - hoy muy radicalizado en las universidades norteamericanas- vindicativo de las ancestrales civilizaciones precolombinas como la más auténtica raíz de sus naciones actuales, a las que la conquista española privó de un devenir mítico y providencial. De ahí que en la época colonial, que tampoco hay que glorificar, sólo vean un drama objeto de desprecio, un tiempo de barbarie e infinitos oprobios al que niegan cualquier atisbo de aportación positiva y del que se debe prescindir como objeto de estudio. De serlo, no es sino para idealizar el pasado de las poblaciones autóctonas o magnificar la vesania e inhumana codicia de los invasores. No obstante, esta mirada selectiva sí da primacía a la etapa final de la colonia, es decir, a la de disolución e insurgencia que propició la liberación del yugo opresor y la gestación de las futuras patrias independientes. Las entidades políticas alternativas que, así, recuperaban el pasado y la continuidad histórica interrumpida con la llegada de los europeos.

Las investigaciones, por ello, suelen concentrarse en los primeros años de vida independiente de los nuevos estados, en aras del enaltecimiento de los logros nacionales que trajo consigo la anulación del poder metropolitano, pero al margen de toda perspectiva temporal. En lo que a nosotros atañe, por ejemplo, la supresión de la Inquisición, la generalización de la imprenta y una supuesta libertad de expresión y prensa. No obstante, parece que en el presente se van abriendo paso corrientes de opinión a favor de juicios más equilibrados y menos pasionales, gracias al avance de las investigaciones y del sentido común. Carlos Fuentes escribía en 1997 que «nos ha tomado tiempo darnos cuenta de que nuestra relación con España es tan conflictiva como nuestra relación con nosotros mismos... La medida de nuestro odio es idéntica a la medida de nuestro amor» ${ }^{53}$; pero ¿no son éstas maneras diferentes de nombrar la pasión? Mas las nuevas repúblicas independientes pronto serían víctimas de la fragmentación política, los conflictos internos, las extremas desigualdades económicas y de derechos y, en última instancia, los gobiernos corruptos e incompetentes de las elites criollas que ocuparon el vacío que había dejado España. Quizás nuestros complejos de madrastra patria no hayan ayudado mucho en la comprensión de esta complejísima historia; pero de una vez nos toca asumir, con responsabilidad, aquel trasunto tal como fue, sin sentimientos

${ }^{53}$ Fuentes, 1997: 22. González Sánchez, 1999; 2008. 
de culpa descontextualizados y al albur de quienes depositan fines bastardos en su manipulación. Baste imitar a ingleses, franceses y holandeses. Unos y otros, queramos o no, hemos de aceptar que el pasado de México o Perú está antes en la Nueva España y en el Reino andino que en el Anahuac y el Incario.

La solución de muchos de los entresijos atrás esbozados y de esta cortedad de miras podría estar en una historia de la cultura escrita de toda América (española, portuguesa, inglesa, francesa y holandesa), encuadrada en una encrucijada atlántica compartida, el Nuevo Mundo de los europeos, capaz de superar una historiografía de las Américas empeñada en destacar diferencias y disparidades entre Europa y América, antes que los prolijos nexos de unión que el gran Océano ha venido conformando ${ }^{54}$. Este reto metodológico ya fue una reivindicación de eminentes bibliófilos estadounidenses del siglo XIX como Obadiah Rich, James Lenox y John Carter Brown, cuyos objetivos bibliográficos y epistemológicos mantendrían la Bibliotheca Americana Vetustissima de Henry Harrisse y la Bibliotheca Americana de Joseph Sabin, ambas de 1866, o la excelente European Americana de John Alden y Dennos Landis ${ }^{55}$. Una magna empresa, al servicio de la comunidad académica, derivada de estas inquietudes fue la John Carter Brown Library, la gran biblioteca fundada desde la convicción de la existencia de una historia común de las Américas ${ }^{56}$.

La tradición historiográfica norteamericana, no obstante y según vimos, arraigó un estudio de las Trece Colonias como entes aislados -la mejor forma de crear una «nación de chovinistas» dice Elliott- con la intención de resaltar su excepcionalidad, originalidad y diferencias respecto al resto del Continente ${ }^{57}$, sin ser consciente de sus propias disimilitudes internas, de que Virginia también difiere de Nueva Inglaterra. A ello se debe que hasta hoy, el tratamiento de cada una de las colonias norteamericanas se suela afrontar mediante el estudio de sus diversas comunidades locales, la premisa, idealista y microscópica, de una historia nacional propiciatoria del excepcionalismo americano $^{58}$. El resultado ha sido una historia, sólo de blancos europeos, que exhibe el éxito del Norte frente al fracaso del Sur; aunque en realidad no fueran tantas las divergencias entre los dos hemisferios coloniales enfrentados. Cierto es que en la América británica la Biblia acaparó un protagonismo ausente en la ibérica, pero en ambas sus pobladores tuvieron en el libro y

54 Bailyn, 1960.

${ }^{55}$ Rich, 1835; 1846. Lenox, 1861. Harrisse, 1866.

56 Elliott, 1998. Se trata de una conferencia impartida con ocasión del 150 aniversario de la Biblioteca. Johnson, 1988.

${ }^{57}$ Del mayor interés es Greene, 1993.

${ }^{58}$ Howe, 1993. 
en el escrito un referente primordial de sus prácticas religiosas: catecismos, almanaques, salterios, tratados piadosos o manuales de oración colmaban la demanda del Nuevo Mundo en un tiempo en el que la religión era la ideología por excelencia.

Incluso hay quien interpreta la colonización puritana de Nueva Inglaterra como una continuación de los modelos ibéricos, y no cual la abrupta y novedosa ruptura que parece sugerir la historiografía empeñada en ver en las sociedades puritanas formaciones radicalmente diferentes a las instituidas en las Indias por el catolicismo español ${ }^{59}$. Tampoco la censura es privativa de la del Centro y Sur; ni las aficiones y obligaciones lectoras de una y otra fueron antagónicas, al menos así lo puso de relieve I. Leonard contrastando surtidos de libreros de Boston y México en 1683. Unos negocios que, de la misma forma, ofertaban devocionarios, sermones, teología moral, historia, derecho, clásicos grecolatinos y literatura de ficción ${ }^{60}$. Es más, Fernández Armesto demuestra cómo el Sur superó al Norte en términos demográficos, urbanos, políticos y culturales durante los siglos modernos, época en la que el primero también gana en secularización e individualismo; y concluye Armesto: «El hemisferio occidental americano comienza a reducirse de tamaño tan pronto como acaba el periodo colonial británico-americano» ${ }^{61}$.

Lamentablemente, una historiografía latinoamericana presa de sí misma, desde la liberal del siglo XIX, viene asumiendo la retórica del declive del sur respecto al norte, un trágico discurso propio de la leyenda negra y sus tópicos que R. Kagan denomina el «paradigma Prescott» ${ }^{62}$. A William H. Prescott (1796-1859), en efecto, debemos la revitalización de la «leyenda negra» protestante para explicar el atraso del mundo hispánico y el meteórico auge de los Estados Unidos a lo largo de la Modernidad ${ }^{63}$. Esta tendencia intenta contrarrestarla Herbert E. Bolton (1870-1953) desde 1933 promocionando una historia de América que superase las tradicionales perspectivas nacionales, en especial la de los Estados Unidos al margen del resto del Continente ${ }^{64}$. Bolton, claro está, contribuyó a crear un clima contrario a estas descripciones simplistas y a favor de las realizaciones de los españoles en América, que sus discípulos desplegaron en monografías de impacto; entre ellos Irving. A.

59 Cañizares-Esguerra, 2008.

${ }^{60}$ Leonard, 1990. González Sánchez, 1999; 2011. Rueda Ramírez, 2005.

${ }^{61}$ Fernández Armesto, 2003; hay una versión castellana en Debate, 2004.

${ }^{62}$ Kagan, 1998: 324-348.

${ }^{63}$ Pese al denodado avance de la investigación sobre la historia de la cultura escrita en el mundo hispánico, muchos de los tópicos de la leyenda negra se siguen reproduciendo, Báez, 2004; 2009.

${ }^{64}$ Bolton, 38 (Chicago, 1933): 448-474. 
Leonard, el autor de Books of the brave, que prefirió cambiar el negro de la leyenda por un gris claro ${ }^{65}$.

En los últimos años, sin embargo, está aumentando el número de historiadores, liderados por J. Elliott, dispuestos a reivindicar que la trayectoria histórica de Estados Unidos comparte los mismos problemas con otras partes del mundo, asequibles desde presupuestos metodológicos abiertos y compa$\operatorname{rados}^{66}$. La historia de las Américas, por tanto, tiene un sentido más claro si se examina interrelacionando sus distintas partes $y$, antes que nada, como un todo indisociable fruto de un océano y un continente comunes. Una meta posible si convertimos el Atlántico, al igual que el Mediterráneo, en la auténtica clave de unión de las dos mitades del mundo, o sea, una viable y eficaz unidad de estudio capaz de engullir los contextos nacionales de la historiografía ensimismada y provinciana. En este sentido, el enfoque transnacional y el método comparativo quizás nos presten un horizonte renovador y pleno de posibilidades. Al hilo, J. Cañizares-Esguerra, como Gruzinski o nosotros, ferviente atlantista, argumenta que la historia de la América colonial británica es la historia de las grandes migraciones atlánticas y del contacto multicultural de europeos, indígenas y africanos, en una red de circuitos comerciales, intelectuales, culturales y políticos ${ }^{67}$.

Elliott es rotundo cuando dirime que América, al igual que Europa, tiene una historia común, porque ambas desarrollan una misma civilización y comparten experiencias y rasgos en un pasado donde las semejanzas prevalecen sobre las diferencias. Todo ello no impide la diversidad y las grandes diferencias de estructura y experiencia histórica; ni admitir que la cultura americana no fue una réplica exacta de la europea. Ha llegado la hora, pues, de buscar el equilibrio entre las percepciones del Norte y las del Sur, de superar unas perspectivas nacionalistas y patrióticas impulsoras del neopositivismo y, por la falta de integración del análisis historiográfico en marcos generales, de una historia tendenciosa empeñada en resaltar hechos diferenciales que limitan la amplitud de miras propia del conocimiento científico.

La historia del libro, y de la cultura escrita en general, más que ninguna, debe ser transnacional, porque el libro, dada su naturaleza infinitesimal, no tiene ni respeta límite alguno, ya sea geográfico, lingüístico, mental, identitario o racial. Un axioma que gana fiabilidad y posibilidades si traemos a colación la dependencia de América de la importación tipográfica de unas metrópolis (España, Inglaterra y Portugal) a su vez pertenecientes a la periferia de

\footnotetext{
${ }^{65}$ Leonard, 1949. Hay varias ediciones en castellano en Fondo de Cultura Económica.

${ }^{66}$ Elliott, 2002; 2010.

${ }^{67}$ Cañizares-Esguerra, 2007. Al respecto Gruzinski, 2005; 1999.
} 
la imprenta europea y, por tanto, dependientes del centro productor (Italia, Francia, Alemania, Países Bajos). He aquí que la historia del libro atlántico colonial anule cuanta frontera encuentre y también asuma el pasado de Italia, Flandes, Alemania, Francia y Holanda o de cualquier otro lugar que tuviere el objeto demandado. Esta historia, hija de los libros, nunca acaba, diluye la realidad en la ficción, los vencedores en los vencidos, y viceversa; el Viejo y el Nuevo Mundo en un océano cultural sincrético.

\section{BiBLIOGRAFÍA}

Abreu, Marcia, História de cordéis e folletos, Campinas, Mercado de Letras, 1999.

Abreu, Marcia, "Da maneira correta de ler: leituras das Belas Letras no Brasil colonial”, Marcia Abreu (org.), Leitura, história e história da leitura, Campinas, Mercado de Letras, 2000a: 249-260.

Abreu, Marcia, "Leituras Coloniais", Atas do II Congreso Luso-Brasileiro de História da Educaçâo, Sâo Paulo, FEUSP, 2000b: 201-206.

Abreu, Marcia, "Leituras no Brasil colonial", Remate dos males, 22 (Sâo Paulo, 2002): 131-163.

Abreu, Marcia, Os Caminhos dos livros, Campinas, Mercado de Letras, 2003.

Abreu, Marcia y Schapochnik, Nelson (orgs.), Cultura letrada no Brasil: objetos e prácticas, Campinas, Mercado de Letras, 2005.

Abreu, Marcia, "Censure et Critique. Les réactions des premiers lecteurs de romans", Cahiers du Brésil Contemporain, 69-70 (París, 2008a): 11-35.

Abreu, Marcia, "La libertad y el error: la acción de la censura luso-brasileña (17691834)", Cultura Escrita \& Sociedad, 7 (Gijón, 2008b): 118-141.

Abreu, Marcia (org.), Trajetórias do Romance. Circulaçâo, leitura e escrita nos séculos XVIII e XIX, Campinas, Mercado de Letras, 2008c.

Abreu, Marcia, "De la fe en Dios a la Brasilidad: una historia del libro y de la lectura en la Verdadera historia y descripción de un país de salvajes de Hans Staden", Manuel F. Fernández, Carlos Alberto González y Natalia Maillard (comps.), Testigo del tiempo, memoria del universo. Cultura escrita y sociedad en el mundo ibérico (siglos XV-XVIII), Barcelona, Rubeo, 2009: 10-22.

Abreu, Marcia y Bragança, Aníbal (orgs.), Impresso no Brasil: duzentos anos de livros brasileiros, Sâo Paulo, Unesp, 2010.

Amory, Hugh, First Impressions.Printing in Cambridge, 1639-1989, Cambridge, Harvard University Press, 1989. 
Amory, Hugh, Bibliography and the Book Trades. Studies in the Print Culture of Early New England, Philadelphia, University of Pennsylvania Press, 2005.

Andrada e Silva, José, Coleçâo Cronológica de Legislaçâo Portuguesa (1603-1612), Lisboa, 1854.

Araújo Antunes, Álvaro de, “Consideraçôes sobre o domínio das letras nas Minas setecentistas”, Locus: Revista deHistória, 6 (Juiz de Fora, 2000): 9-20.

Araújo de Alvarenga, Thábata, Homens e Livros em Vila Rica (1750-1800), Sâo Paulo, FFLCH-USP, 2003.

Axtell, James, Natives and Newcomers. The Cultural Origins of North America, Oxford, Oxford University Press, 2001.

Báez, Fernando, Historia universal de la destrucción de libros, Barcelona, Destino, 2004.

Báez, Fernando, El saqueo cultural de América Latina. De la conquista a la globalización, Madrid, Debate, 2009.

Bailyn, Bernard, Education in the Forming of American Society, New York, London, 1960.

Bailyn, Bernard y Hench, John B. (eds.), The Press and the American Revolution, Worcester, AAS, 1980.

Bailyn, Bernard, Atlantic history: concept and contours, Cambridge, Harvard University Press: 2005.

Barber, Giles "Books from the Old World and for the New: The British International Trade in Books in the Eighteenth Century", Studies on Voltaire and Eighteenth Century, 151 (Oxford, 1976): 185-224.

Bastos Pereira das Neves, Lúcia Maria, "Comercio de livros e censura de ideáis no Brasil: a atividade dos livros franceses no Brasil e a vigilancia da Mesa do Desembargo do Paço (1795-1822)", Ler História, 23 (Lisboa, 1992): 61-78.

Bastos Pereira das Neves, Lúcia Maria, "Censura, Circulaçâo de ideáis e Esfera Pública de Poder no Brasil, 1808-1824”, Revista Portuguesa de História, 33 (Coimbra, 1999): 665-697.

Bethencourt, Francisco, História das Inquisiçoes: Portugal, Espanha e Itália: Séculos $X V$-XIX, Sâo Paulo, Companhia das Letras, 2000.

Blanck, Jacob, Bibliography of American Literature, New Haven, Yale University Press, 1955.

Bennassar, Bartolomé, La América española y la América portuguesa: siglos XVIXVIII, Madrid, Akal, 1980.

Bolton, Herbert E., «The Epic of Greater America», American Historical Review, 38 (Chicago, 1933): 448-474. 
Borba de Moraes, Rubem, Bibliografía brasileira do periodo colonial, Sâo Paulo, IEB, 1969.

Borba de Moraes, Rubem, Livros e Bibliotecas no Brasil Colonial, Sâo Paulo, Secretaria da Cultura, 1979.

Bristol, Roger P., Evans'American Bibliography. Supplement, Charlottesville, University of Virginia, 1962.

Bugbee, Bruce W., Genesis of American Patent and Copyright Law, Washington DC, Public Affairs Press, 1967.

Cañizares-Esguerra, Jorge, Cómo escribir la historia del Nuevo Mundo: historiografias, epistemologías e identidades en el mundo del Atlántico del siglo XVIII, México, Fondo de Cultura Económica, 2007.

Cañizares-Esguerra, Jorge, Católicos y puritanos en la colonización de América, Madrid, Marcial Pons, 2008.

Carneiro, Maria Luíza, História da Censura no Brasil, Sâo Paulo, Edusp, 2002.

Cave, Roderick, Printing and the Book Trade in the West Indies, London, Pindar Press, 1987.

Clegg, Cyndia S., Press Censorship in Elizabethan England, New York, Cambridge University Press, 1997.

Cogley, Richard, John Eliot's Mission to the Indians before King Philip's War, Cambridge, Cambridge University Press, 1999.

Cremin, Lawrence A., American Education: The Colonial Experience, 1607-1783, New York, Harper \& Row, 1970.

Cushing, John D. (ed.), The Earliest Printed Laws of Pennsylvania, 1681-1713, Wilmington, Michael Glazier, 1981.

Davidson, Cathy N., Reading in America. Literature \& Social History, Baltimore, John Hopkins University Press, 1989.

Dias Tavares, Luiz E., Introduçâo ao estudo das ideáis do movimento revolucionário de 1798, Salvador, Livraria Progresso Editora, 1959.

Diniz, Silvio G., "Bibliotecas setecentistas nas Minas Gerais", Revista do Instituto Histórico e Geográfico de Minas Gerais, 6 (Belo Horizonte, 1959): 333-344.

Elliott, John H., ¿Tienen las Américas una Historia Común? Una conferencia, Rhode Island, John Carter Brown Library, 1998.

Elliott, John H., España en Europa: estudios de historia comparada, Valencia, Universidad de Valencia, 2002.

Elliott, John H., Imperios del mundo atlántico. España y Gran Bretaña en América (1492-1830), Madrid, Taurus, 2006. 
Elliott, John H., España, Europa y el mundo de ultramar (1500-1800), Madrid, Taurus, 2010.

Éllis, Myriam, "Documentos sobre a primeira biblioteca pública oficial de Sâo Paulo", Revista de História, 30 (Sâo Paulo,1957): 387-447.

Evans, Charles T., American Bibliography, 1630-1820, 14 vols., Chicago, 1903-1959.

Fausto, Boris, A Concise History of Brazil, Cambridge, Cambridge University Press, 2005.

Fernández Armesto, Felipe, The Americas: A Hemispheric History, New York, Ransom House, 2003.

Ford, Worthington C., The Boston Book Market, 1679-1700, Boston, Club of Odd Volume, 1917.

França Paiva, Eduardo, História \& Imagens, Belo Horizonte, Auténtica, 2006.

Franklin, Benjamin V., Boston Printers, Publishers, and Booksellers, 1640-1800, Boston, G. K. Hall, 1980.

Frieiro, Eduardo, O Diabo na livraria do Cônego, Belo Horizonte, Itatiaia, 1981.

Fuentes, Carlos, El espejo enterrado, Madrid, Taurus, 1997.

Gallegos, Bernardo P., Literacy, Education, and Society in New Mexico, 1693-1821, Albuquerque, University of New Mexico Press, 1992.

García Aguilar, Idalia y Rueda Ramírez, Pedro (comps.), Leer en tiempos de la colonia, México, Universidad Nacional Autónoma de México, 2010.

Gomes Leite, Paulo, "Leitores e lecturas em Mariana nos séculos XVIII e XIX", Revista do Instituto Histórico e Geográfico de Minas Gerais, 24 (Belo Horizonte, 2001): 217-226.

González Sánchez, Carlos A., Los mundos del libro. Medios de difusión de la cultura occidental en las Indias de los siglos XVI y XVII, Sevilla, Universidad de Sevilla, 1999.

González Sánchez, Carlos A., Atlantes de papel. Adoctrinamiento, creación y tipografía en la Monarquía Hispánica de los siglos XVI y XVII, Barcelona, Rubeo, 2008.

González Sánchez, Carlos A., New World Literacy. Writing and Culture Across the Atlantic, 1500-1700, Lewisburg, Bucknell University Press, 2011.

Greene, Jack P., The Intellectual Construction of America: Exceptionalism and Identity from 1492 to 1800, Chapel Hill, University of North Carolina Press, 1993.

Gruzinski, Serge, La Pensée métisse, Paris, Fayard, 1999.

Gruzinski, Serge, Les Quatre parties du Monde. Histoire d'une mondialisation, Paris: Éditions de La Martinière, 2005.

Hall, David D., "Introduction: The Uses of Literacy in New England, 1600-1850", W. L. Joyce, D. D. Hall, R. Brown y J. B. Hench (eds.), Printing and Society in Early America, Worcester, American Antiquarian Society, 1988: 1-47. 
Hall, David D., Worlds of Wonder, Days of Judgement. Popular Religious Beliefs in Early New England, New York, Knopf, 1989.

Hall, David D., Cultures of Print. Essays in the History of the Book, Boston, University of Massachussets Press, 1996.

Hall, D. D. (ed.), A History of the Book in America, 5 vols., New York y Cambridge, University Press, 2000.

Hall, David D., "Hambre de libros: la "República de las Letras" en la América moderna", Cultura Escrita y Sociedad, 2 (Gijón, 2006): 108-127.

Hall, D. D. y Amory, H. (eds.), The Colonial Book in the Atlantic World, New York y Cambridge, University Press, 2000.

Harrisse, Henry, Bibliotheca Americana Vetustísima (1492-1551), New York, G. P. Philes, 1866.

Horta Nunes, José, Formaçâo do leitor brasileiro: imaginário da leitura no Brasil colonial, Campinas, UNICAMP, 1994.

Howe, Daniel W., American History in an Atlantic Context, Oxford, Oxford University Press, 1993.

Johnson, Julie G. (ed.), The Book in the Americas. Providence, John Carter Brown Libray, 1988.

Kagan, Richard, "Prescott's Paradigm: American Historiacal Scholarship and the Decline of Spain", A. Molho y G. S. Woods (eds.), Imagined Histories, Princeton, Priceton University Press, 1998: 324-348.

Lafaye, Jacques, "Literatura y vida intelectual en la América española colonial", L. Bethell (ed.), Historia de América latina, 4: América latina colonial: población, sociedad y cultura, Barcelona, Crítica, 1990: 229-261.

Lajolo, Marisa y Zilberman, Regina, A lectura rarefeita: livro e literatura no Brasil, Sâo Paulo, Brasiliense, 1991.

Lajolo, Marisa y Zilberman, Regina, A formaçâo da leitura no Brasil, Sâo Paulo, Ática, 1996.

Leite, Serafín, História de Companhia de Jesús no Brasil, Lisboa / Rio do Janeiro, Portugalia / INL, 1938-1950.

Lenox, James, The Early Editions of King James'Bible in folio, New York, 1861.

Leonard, Irving A., Books of the Brave. Being an account of Books of Men in the Spanish Conquest and Settlement of the Sixteenth Century New World, Cambridge, Harvard University Press, 1949.

Leonard, Irving A., La época barroca en el México colonial, México, Fondo de Cultura Económica, 1990. 
Lockhart, James y Schwartz, Stuart, América Latina en la Edad Moderna: una historia de la América española y Brasil coloniales, Madrid, Akal, 1992.

Lockridge, Kenneth A., Literacy in Colonial New England: An Inquiry into the Social Context of Reading in the Early Modern West, New York, W. W. Norton, 1974.

Machado, Alcântara, Vida e morte do bandeirante, Sâo Paulo, Edusp, 1980.

McMurtrie, Douglas C., The Bibliography of American Imprints, Ann Arbor, University of Michigan Press, 1994.

Mezan Algranti, Leila, "Os livros de devoçâo e a religiosa perfecta: normatizaçâo e prácticas religiosas nos recolhimentos femeninos no Brasil colonial", Cultura portuguesa na Terra de Santa Cruz, Lisboa, Estampa, 1995: 109-124.

Mezan Algranti, Leila, "Política, religiâo e moralidade: a censura de livros no Brasil de D. Joâo VI (1808-1821)", Maria Luiza Tucci Carneiro (org.), Minorias silenciadas: história da censura no Brasil, Sâo Paulo, Universidade do Sâo Paulo, 2002.

Mezan Algranti, Leila y Megiani, Ana Paula (orgs.), Escrita, memória e vida material: formas de transmissâo da cultura letrada no império Portugués (séculos XVI-XIX), Sâo Paulo, Alameda, 2007.

Mezan Algranti, Leila y Megiani, Ana Paula (orgs.), O Império por escrito. Formas de transmissâo da cultura letrada no mundo ibérico séculos XVI-XIX, Sâo Paulo, Alameda, 2009.

Miller, William C., Benjamin Franklin's Philadelphia Printing, 1728-1766: A Descriptive Bibliography, Philadelphia, American Philosophical Society, 1974.

W. E. Minchinton y C. J. French, Customs 3, 1696-1780 in the Public Record Office, London, East Ardsley, Wakefield, EP Microfilm, 1974.

Mott, Luiz, A Inquisiçâo no Sergipe, Aracaju, FUNDESC, 1989.

Neumann, Eduardo, "Escribiendo en la frontera del Paraguay: prácticas de la escritura guaraní durante la demarcación de límites (siglo XVIII)", Cultura Escrita \& Sociedad, 7 (Gijón, 2008): 159-190.

Nizza da Silva, Maria Beatriz, Cultura e sociedade no Rio de Janeiro (1808-1821), Sâo Paulo, Companhia Editora Nacional, 1978.

Nizza da Silva, Maria Beatriz, A cultura luso-brasileira: da reforma de Universidade à Independencia do Brasil, Lisboa, Estampa, 1999.

Parker, George L., The Beginnings of the Book Trade in Canada, Toronto, University of Toronto Press, 1985.

Queiros Mattoso, Katia de, Presença Francesa no Movimento Democrático Baiano de 1798, Salvador, Itapuâ, 1969.

Raven, James, "Commodification and Value: Interactions in Book Traffic to North America, c. 1750-1820”, B. Bell, Ph. Bennett y J. Bevan (eds.), Across Boundaries. The Book in Culture \& Commerce, New Castle, Oak Knoll Press, 2000a: 73-90. 
Raven, James, London Booksellers and American Customers: Transatlantic Community, Literary Conduits, and the Charleston Library Society, 1748-1811, Columbia, University of South Carolina Press, 2000b.

Remer, Rosalind, Printers and Men of Capital. Philadelphia Book Publishers in the New Republic, Philadelphia, University of Pennsylvania Press, 2000.

Rhys, Isaac, The Transformation of Virginia, 1740-1790, Chapel Hill, University of North Carolina Press, 1982.

Ribeiro, Marília de Azambuja, "Livros defesos e bibliotecas privadas no Brasil em finais do século XVI", Historia: cultura e sentimento. Outras Histórias do Brasil, Recife-Cuiabá, Anexo, 2008.

Ribeiro de Lessa, Clado, "As bibliotecas brasileiras dos tempos coloniais: apontamentos para um estudo histórico", Revista do Instituto Histórico e Geográfico Brasileiro, 191 (Sâo Paulo,1946): 339-345.

Rice, Grantland S., The Transformation of Authorship in America, Chicago, University of Chicago Press, 1997.

Rich, Obadiah, Bibliotheca Americana Nova, London, Adlar, 1835.

Rich, Obadiah, A Catalogue of Books Relating to America, London, Rich, 1846.

Rizzini, Carlos, "Um livreiro em Vila Rica no meado do século XVIII", Kriterion, 47/48 (Salszburgo, 1959): 180-198.

Rizzini, Carlos, O livro, o Jornal e a Tipografia no Brasil (1500-1822), Sâo Paulo, Imprensa Oficial do Estado, 1988.

Rueda Ramírez, Pedro J., Negocio e intercambio cultural: el comercio de libros con América en la Carrera de Indias (siglo XVII), Sevilla, Universidad de Sevilla, 2005.

Sabin, Joseph, A Dictionary of Books Relating to America, from its Discovery to the Present Time, 29 vols., New York, 1868-1936.

Shields, David S., Civil Tongues and Polite Letters In British America, Chapel Hill, University of North Carolina Press, 1996.

Shipton, Clifford K. y Mooney, James E., National Index of American Imprints through 1800: The Short-Title Evans, 2 vols., Worcester, American Antiquarian Society, 1969.

Siquiera, Sonia A., A Inquisiçâo e a Sociedade Colonial, Sâo Paulo, Ática, 1978.

Souza Araújo, Jorge de, Perfil do lector colonial, Salvador, Ilhéus, 1999.

Stout, Harry S., The New England Soul: Preaching and Religious Culture in Colonial New England, New York, Oxford University Press, 1986.

Suarez, Michael F., "Historiographical Problems and Possibilities in Book History and National Histories of the Book", Studies in Bibliography, 56 (Charlottesvi1la,2003-2004): 140-170. 
Tanselle, Thomas, "Some Statistics on American Printing, 1764-1783", B. Bailyn and J. B. Hench (eds.), The Press and the American Revolution, Worcester, American Antiquarian Society, 1980: 319.

Thomas, Isaiah, The History of Printing in America, 2 vols., Worcester, Massachussets, 1810.

Thomas, Werner y Stols, Eddy (eds.), Un mundo sobre papel. Libros y grabados flamencos en el Imperio Hispanoportugués (siglos XVI-XVIII), Lovaina, Editorial Acco, 2009.

Tremaine, Marie, A Bibliography of Canadian Imprints, 1751-1800, Toronto, University of Toronto Press, 1952.

Vaughan, Alden T., New England Frontier. Puritans and Indians 1620-1675, Oklahoma, University of Oklahoma Press, 1995.

Verri, Gilda M., Tinta sobre papel: livros e lectura na Capitania de Pernambuco (1759-1808), Recife, Editora da UFPE, 2006.

Villalta, Luiz Carlos, “O Diabo na livraria dos Inconfidentes”, Adauto Novaes (org.), Tempo e História, Sâo Paulo, Companhia das Letras, 1992: 267-295.

Villalta, Luiz Carlos, “Os clérigos e os livros em Minas Gerais na segunda metade do século XVIII”, Acervo, 8 (Belo Horizonte, 1995): 19-52.

Villalta, Luiz Carlos, "Bibliotecas privadas e prácticas de lectura no Brasil colonial”, Naissance du Brasil Moderne, París, PUF, 1998.

Villalta, Luiz Carlos, "Censura literária e inventividade dos lectores no Brasil colonial”, Minorias silenciadas: história da censura no Brasil.Reformismo Ilustrado, Censura e Prácticas de Lectura: Usos do Livro na América Portuguesa, Sâo Paulo, FFLCH-USP, 1999.

Villalta, Luiz Carlos, "Os leitores e os usos dos livros na América portuguesa”, Marcia Abreu (org.), Leitura, História e História da Leitura, Campinas, Companhia de Letras, 2000: 183-212.

Villalta, Luiz Carlos, "A história do livro e da lectura no Brasil Colonial: balanço historiográfico e proposiçao de uma pesquisa sobre o Romance”, Convergencia Lusíada, 21 (Lisboa, 2005): 165-185.

Villalta, Luiz Carlos, "Viajes y prácticas de lecturas en el Brasil colonial: Robinson Crusoe, novela, historia y estilo", Cultura Escrita y Sociedad, 2 (Gijón, 2006): 128-160.

Villalta, Luiz Carlos, “Censura literaria en el mundo luso-brasileño (1517-1808): órganos censores, criterios de censura y obras prohibidas", Cultura Escrita y Sociedad, 7 (Gijón, 2008): 98-117.

Villalta, Luiz Carlos, “Cultura letrada y estratificación social en la Capitanía de Minas, Brasil: las bibliotecas y las habilidades de leer y escribir”, Manuel F. Fernández, 
Carlos Alberto González y Natalia Maillard (comps), Testigo del tiempo, memoria del universo. Cultura escrita y sociedad en el mundo ibérico (siglos XV-XVIII), Barcelona, Rubeo, 2009: 175-206.

Warner, Michael, The Letters of the Republic: Publication and the Public Sphere in Eighteenth-Century America, Cambridge, Harvard University Press, 1990.

Wegelin, Oscar, Early American Poetry. A Compilation of the Titles of Volumes of Verse and Broadsides, Written by Writers Born or Residing in North America, 2 vols., New York, The Literary Collector Press, 1903.

Edwin Wolf, The Book Culture of a Colonial American city, Oxford, Clarendon Press, 1988.

Woodmansee, M. y Jaszi, P. (eds.), The Construction of Authorship: Textual Appropiation in Law and Literature, Durham, Duke University Press, 1994.

Wroth, Lawrence C., A History of Printing in Colonial Maryland, 1686-1776, Baltimore, Typothetae of Baltimore, 1922.

Wroth, Lawrence C., The Colonial Printer, Portland, Southworth-Anthoesen Press, 1938.

Fecha de recepción: 13 de marzo de 2012.

Fecha de aceptación: 1 de junio de 2012.

\section{Written Culture in the Colonial Atlantic World: Brazil and North America. Historiographic Keys, Challenges and Perspectives}

This article seeks a critical assessment on Written Culture of colonials Brazil and North America. Its aim is to set out historiographic balance that allows us a comparative prospect with the rest of the American Continent. As a last resort it wants to provide new study perspectives relating to the need for a common history of the Americas. Perhaps this objective can go beyond the topics and disparate underestandings that distort Atlantic World History.

Key words: written culture; historiography; atlantic world; Brazil; North America. 